\title{
Erratum to: Colorimetric and bare eye determination of urinary methylamphetamine based on the use of aptamers and the salt-induced aggregation of unmodified gold nanoparticles
}

\author{
Qiuna Shi • Yupeng Shi • Yi Pan • Zhenfeng Yue •
}

Heng Zhang • Changqing Yi

Published online: 5 November 2014

(C) Springer-Verlag Wien 2014

\section{Erratum to: Microchim Acta}

DOI 10.1007/s00604-014-1349-8

The original version of this paper, unfortunately, contained an error in one of the authors' names. The name of the first author should be corrected to "Qiuna Shi".

The online version of the original article can be found at http://dx.doi.org/ 10.1007/s00604-014-1349-8.

\section{Q. Shi $(\bowtie)$}

Department of Criminal Science and Technology, Henan Police

College, Zhengzhou, China

e-mail: sqn7908@sohu.com

Y. Shi $\cdot$ Y. Pan $\cdot$ H. Zhang $\cdot$ C. Yi $(\bowtie)$

Key Laboratory of Sensing Technology and Biomedical Instruments

(Guangdong Province), School of Engineering, Sun Yat-Sen

University, Guangzhou 510275, China

e-mail: yichq@mail.sysu.edu.cn

\section{Z. Yue $\cdot$ H. Zhang}

Shenzhen Key Research Laboratory of Detection Technology R\&D on Food Safety, Technical Centre for Food Inspection and

Quarantine, Shenzhen Entry-Exit Inspection and Quarantine Bureau,

Shenzhen 518045, China 